\title{
Hipólito Unanue visto por Augusto Salazar Bondy: La tradición organicista de la ciencia en el Perú
}

\author{
José-Carlos Ballón ${ }^{1}$
}

Resumen

Palabras clave

\begin{abstract}
Existe una suerte de consenso entre los historiadores de las ideas en el Perú, en caracterizar a Unanue y los jóvenes que con él se agruparon en la revista Mercurio Peruano (1790-1795) como fundadores del pensamiento ilustrado en el Perú. No obstante, una minuciosa investigación textual de la obra científica de Hipólito Unanue muestra la presencia de un paradigma de cientificidad natural que operaba con categorías y perspectivas notoriamente divergentes de la tradición mecanicista ilustrada. Unanue refleja en una misma época y en un mismo espíritu científico el entrecruzamiento de dos paradigmas en disputa desde el siglo XVII: el de la 'razón' físico-matemática, que se opone al de la razón histórico-natural. Voy a sostener la hipótesis de que la opción epistemológica de Unanue no fue un asunto personal sino una característica histórica persistente de nuestra comunidad científica. En ella se evidencia una hegemonía del paradigma organicista de la naturaleza y una metodología ligada a las ciencias biológicas. Tal vez, dicho examen nos puede ayudar a evaluar hoy tanto nuestras debilidades como nuestras ventajas comparativas en la tarea de desarrollar una cultura científica moderna en el Perú. Es posible que el predominio de la tradición organicista en nuestra comunidad científica nacional haya sido un fuerte obstáculo para el desarrollo de ciertas disciplinas científicas en las que fructificó el paradigma mecanicista (particularmente en las ciencias físicas). Pero es también cierto que el paradigma organicista constituyó un fuerte estímulo para el desarrollo de las llamadas ciencias biológicas, las cuales han alcanzado importante desarrollo en el Perú.

Perú, historia de la medicina; ciencias biológicas; organicismo; Unanue, Hipólito; ciencia.
\end{abstract}

\begin{abstract}
Hipolito Unanue as seen by Augusto Salazar Bondy: The organicist tradition of science in Peru Abstract

There is a sort of consensus on ideas on Peru among historians in characterizing Unanue and the young people grouped around him in the journal Mercurio Peruano (1790-1795) as founders of Peru's illustrious thinking. Notwithstanding, a meticulous textual investigation of Hipolito Unanue's scientific work shows the presence of a paradigm of natural scientificity that operated with categories and perspectives notoriously divergent from the illustrated mechanicist tradition. With the same scientific spirit Unanue reflects the intercrossing of two paradigms in dispute since the XVII century: the physicalmathematical reasoning that opposes the historical-natural reasoning. I am going to sustain the hypothesis that Unanue's epistemologic option was not a personal business but a historical characteristic prevalent in our scientific community. It denotes hegemony of the nature's organicist paradigm and a methodology linked to the biological
\end{abstract}

Profesor Principal del Departamento Académico de Filosofía de la Facultad de Letras y Ciencias Humanas de la Universidad Nacional Mayor de San Marcos. Lima, Perú. sciences. Today maybe such exam may help us to determine our weaknesses and comparative advantages in the task of developing a modern scientific culture in Peru. It is possible that the predominance of the organicist tradition in our national scientific community might have been a hard obstacle for the development of certain scientific disciplines where the mechanicist paradigm was fruitful (particularly in the physical sciences). But it is also true that the organicist paradigm represented a strong stimulus for the development of the so called biological sciences that have reached important development in Peru.

Keywords: Peru, history of medicine; biological sciences; organicism; Unanue, Hipolito; science.

La hasta hoy inédita tesis sobre los supuestos filosóficos del pensamiento científico de Hipólito Unanue -con la que el filósofo peruano Augusto Salazar Bondy (1926-74) se graduó como Bachiller en San Marcos en $1950\left(^{1}\right)$ - constituye una de las aproximaciones más interesantes al pensamiento filosófico de Hipólito Unanue y, en general, más sugerente para comprender los paradigmas que han gobernado la evolución del pensamiento científico moderno en el Perú. 
Existe un consenso, entre los historiadores de las ideas en el Perú, en caracterizar a Unanue y los jóvenes ideólogos y científicos que con él se agruparon en la Sociedad Amantes del País y en la revista Mercurio Peruano (1790-1795) como fundadores del pensamiento ilustrado en el Perú. Se estima igualmente que a partir de dicho pensamiento se diseñó el proyecto de constituir el Perú como una república independiente y moderna.

Los temas más importantes del Mercurio fueron la geografía, la historia social, la medicina, la historia natural y la economía política (comercio y minería), sobre todo. Ilustrar a los peruanos significó, para dicha élite, ganarlos a la mirada de la ciencia y el razonamiento modernos en su lectura del país.

Salazar trató de examinar -mediante un análisis textual e histórico de la obra de Hipólito Unanue“...el cuadro mental que refleja la obra del médico peruano, tomando como materia de examen no solo [...] la doctrina científica que hace suya, particularmente la médica [sino la] atmósfera intelectual en la que se formó y de la que recibió sus estímulos teóricos decisivos" *.

\section{La imagen de Unanue como ilustrado}

El estudio de Salazar lo llevó a concluir la presencia del siguiente horizonte paradigmático en su pensamiento: 1) Ideas y sistemas racionalistas afines al cartesianismo. 2) Una filosofía natural afín al copernicanismo y al mecanicismo de Galileo y Newton. 3) Adhesión a las ideas y doctrinas de orientación empirista y sensualista de Locke y Condillac. 4) Afinidad con la filosofía política y jurídica de Montesquieu y Rousseau, con las doctrinas económicas modernas de tipo fisiocrático y mercantilista y con las ideas utilitaristas y liberales de Bentham y Smith. 5) Finalmente, un tipo de asimilación de las ideas ilustradas, caracterizado por José Gaos como de un 'eclecticismo de tipo especial' .

Para llegar a esta caracterización del pensamiento de Unanue, Salazar exploró en la obra de Hipólito Unanue un conjunto de 'ideas fundamentales' ubicadas en una esfera metadiscursiva relativas al

Salazar $\left({ }^{1}\right)$, Introducción, p. 1.

Ibid., capítulo primero: "Las formas del saber".

Ibid., capítulo primero: "Análisis de la ciencia".

Unanue $\left({ }^{3}\right)$, p. 246. sistema de conocimientos, como las de 'razón', 'experiencia', 'método científico', 'filosofía moderna', 'ciencia', 'naturaleza', la propia idea de la 'ilustración', 'religión' y 'Dios', entre otras.

Según Salazar, un rasgo crucial que identificaría el discurso de Unanue con el pensamiento moderno ilustrado se evidencia en la manera como "Unanue habla una y otra vez [...] de la ciencia natural, como saber estricto y opuesto al saber metafísico, que había constituido el meollo de la tradición filosófica escolástica" ${ }^{\dagger}$.

Un segundo rasgo se mostraría en que "toma el hecho del conocimiento como una realidad natural" $\ddagger$, al sugerir que "las ciencias nacen a partir del trabajo cognoscitivo determinado por la exigencia de conservar la vida [...] para satisfacer las más elementales necesidades orgánicas [las cuales] libran al hombre de hallarse a merced de las fuerzas que en su contorno vital le son contrarias y nocivas". Para Unanue $\left({ }^{2}\right)$, "esta vinculación primaria con las urgencias prácticas, determina el orden de aparición de los conocimientos y su valoración por el hombre en el nivel natural".

De estos dos rasgos fundamentales que caracterizan el conocimiento científico, siguen sus dos constituyentes metodológicos esenciales: 'la experiencia y la razón', cuya “conjunción [...] determina el paso del plano de la simple empirie, de la especulación falaz, o del acopio disperso de verdades, a aquel en que se mueve un saber concebido y formulado como sistema", esto es, "como cuerpo coherente de conocimientos fundados" $§$. No obstante su contundencia, estas afirmaciones originan por lo menos tres interrogantes:

1. ¿Cómo entiende Unanue esta ‘experiencia' que se pone como 'base natural' del conocimiento científico?

2. Igualmente, hay que preguntar con Salazar ¿cómo entiende Unanue la ‘idea de razón’ que, al parecer, articula con naturalidad dicha experiencia?

3. Finalmente, ¿en qué medida existe una conjunción entre ellas? y si ambas expresiones tienen una clara filiación ideológica ilustrada.

\section{Su noción de experiencia científica}

No obstante la contundente caracterización inicial de Salazar Bondy acerca de la naturaleza moderno- 
ilustrada del pensamiento de Hipólito Unanue sobre la ciencia, el desarrollo minucioso de su propia investigación textual reveló la presencia de un conjunto de características ideológicas que desbordaban por completo los horizontes señalados. El pensamiento de Unanue mostraba la presencia de un paradigma de cientificidad natural que operaba con categorías y perspectivas notoriamente divergentes de la tradición mecanicista ilustrada, las cuales provenían de un peculiar devenir histórico de la comunidad científica que inició el desarrollo de la ciencia moderna en el Perú.

Lo primero que llamó la atención de Salazar fue la noción 'cualitativa' y 'compleja' que Unanue tenía de la idea de 'experiencia' o 'intuición' como base del conocimiento científico. En efecto, Unanue no compartía la noción puramente extensiva o cuantitativa de 'simplicidad' que Locke daba a las ideas iniciales de origen sensible, ni Descartes a las ideas 'claras y distintas' que se encuentran en la intuición inicial de todo conocimiento científico. En otras palabras, Unanue no parece asumir el postulado lógico de simplicidad expuesto por Leibniz en su 'Monadología'. Se trata de un postulado central de la ciencia mecanicista moderna que coloca a la filosofía natural (física) como ciencia primera, al análisis matemático como su método fundamental (Descartes y Newton) y a la concepción atomista de la naturaleza como su ontología básica.

Si bien Unanue no adhirió a la idea de una 'fundamentación' metafísica de carácter supraempírico y más bien exigió partir de 'un conocimiento intuitivo de las cosas" " y que "la experiencia debe ser el fundamento de todos los raciocinios", su naturalismo no tenía las características puramente extensivas del empirismo ni del racionalismo modernos, ni compartía la cinemática de la mecánica teórica moderna, sino un cierto tipo de visión organicista de la naturaleza y el conocimiento científico. Conviene al respecto recordar el título que Unanue puso a su obra

1I "El intuitivo conocimiento de las cosas es el que debe preceder como indispensable para que se rectifiquen con acierto, ampliando o restringiendo sus partes integrantes" $\left({ }^{4}\right)$.

$9 \quad$ Unanue $\left({ }^{5}\right)$.

** Unanue $\left({ }^{6}\right)$.

$\dagger$ Unanue $\left({ }^{2}\right)$. principal: Observaciones sobre el clima de Lima y su influencia en los seres organizados, en particular el hombre [1806] ${ }^{\text {. }}$.

La complejidad inicial de la experiencia científica tiene para Unanue un fundamento natural; su «trabajo cognoscitivo está determinado por la exigencia de conservar la vida [...] para satisfacer las más elementales necesidades orgánicas». No es una sensibilidad simple sino orgánica la que obliga a su gnoseología a asumir la presencia de una potencia distinta a la 'receptividad sensorial simple o refleja', como supone la visión empirista y mecanicista del conocimiento. Así, por ejemplo, cuando caracteriza la actividad clasificadora de los seres vivos en la zoología, la define como una "actitud que puede llamarse [...] inducción tipificadora propia de las ciencias históriconaturales". Lo característico de ellas sería ese novum que agrega al dato sensible, ese 'crear seres generales' -del cual hablaba D'Alembert-, que, "separados abstractamente de su sujeto, no pertenecen ya al resorte inmediato de nuestros sentidos" **. Lo mismo ocurre con la botánica, donde la ordenación sistemática en 'géneros y especies' capaces de albergar un individuo vegetal y unificar la 'observación botánica', bajo la cual encuentra explicación el hecho aislado y fugaz obtenido de la experiencia sensorial simple, constituye una reconstrucción de su 'historia natural'.

Por esta razón, toma "la botánica como el más primitivo cuerpo de conocimientos de que dispone el hombre". Las plantas -dice Unanue- fueron estudiadas "antes de arreglar los movimientos del planeta rector del universo y observar la marcha majestuosa del resto de los astros o escudriñar la generación de los fósiles en los senos ocultos de la tierra" " En la "Disertación sobre la coca" -en clara diferencia con Locke- Unanue le da a la botánica el título de 'primer ensayo filosófico del entendimiento humano' $\left({ }^{7}\right)$.

\section{Su noción de racionalidad}

Estas consideraciones conducen a Salazar a la siguiente pregunta: ¿Qué será para Unanue la razón y cuáles sus modos de articularse con la experiencia? Recordemos que para la gnoseología moderna la relación entre la experiencia y la razón se plantea problemática, pues no hay una solución de 
continuidad entre ambas ${ }^{*}$. La naturaleza cartesiana o newtoniana era una sustancia invariante, inerte y simple, cuya única propiedad intrínseca era la extensión, a partir de la cual sus cambios se gobiernan por una causalidad local directa (choque, rozamiento u oscilación de un medio), desapareciendo de la naturaleza toda suerte de potencias, intencionalidades o entelequias. La razón es por el contrario una sustancia pensante inmaterial y activa, cuya propiedad fundamental es la libertad. El postulado de simplicidad y el procedimiento analítico consisten precisamente en procedimientos artificiales para reducir el pensamiento a 'ideas claras y distintas' (Descartes) o 'simples' o 'primarias' (Locke). Se trata de dos sustancias paralelas cuya concordancia o armonía resulta problemática de fundamentar por sus propiedades divergentes. Ello dio lugar al debate entre empiristas y racionalistas, así como a la distinción dualista entre verdades de hecho y verdades de razón. Pues bien, este problema no parece plantearse en los mismos términos para Unanue.

$\mathrm{Su}$ caracterización de la racionalidad como 'discurso exacto' -de aparente factura cartesiana para Salazaralude, sin embargo, a la 'capacidad de elaborar la experiencia y de complementarla trascendiéndola'. Con ello sugiere la idea de un escalonamiento gradual y continuo de la sensibilidad a la racionalidad, basada en una visión genética de la naturaleza como un inmenso organismo vivo, 'fundamento de todos los raciocinios y resultados fisiológicos' *.

$\mathrm{Su}$ noción de racionalidad como capacidad de rebasar la experiencia en tanto mera sensibilidad descriptiva (simple empirie) apunta a una diferenciación de tipo orgánico que incluye una explicación por causas y a la vez opera con la clasificación por géneros y especies de origen clásico (platónico-aristotélico). Esto ha hecho que muchos de nuestros estudiosos de Unanue y del pensamiento filosófico peruano hablen de una suerte de 'eclecticismo especial' para señalar esta curiosa mezcla categórica de elementos tan divergentes.

Pero, bien visto, el aparente carácter inconsistente ('mezcla ecléctica') del discurso de Unanue no es un resultado interno de su propio discurso, sino, más bien, de la caracterización previa que se le atribuyó. Lo que sucede es que, en realidad, Unanue está operando con nociones y categorías conceptuales de tipo organicista y no mecanicista. Estas interpretan los fenómenos naturales en términos de nexos funcionales que se dan en los componentes de un organismo vivo, un paradigma que -en este aspectotenía la ventaja de que no presentaba las aporías filosóficas de la lectura mecanicista de Galileo, Descartes y Newton. Unanue ofrece múltiples ejemplos del uso de esta formulación ${ }^{\dagger}$.

La concepción organicista de la racionalidad no ve a ésta como una sustancia independiente de las res extensa natural, sino como una propiedad emergente de la misma naturaleza, resultado de un proceso 'histórico-natural' de diferenciación de su evolución orgánica. Así, para Unanue, lo que separa la racionalidad del hombre de la del orangután creado para errar en los bosques- era la marcha de su vida social que lo situaba en un plano orgánico jerárquicamente superior, génesis que había generado una especie natural distinta de racionalidad.

Esta visión de la racionalidad es asimismo análoga con su mirada de la naturaleza, no como una sustancia extensa e inerte de carácter corpuscular simple, cuyas relaciones son contingentes, sino como una estructura orgánica compleja entrelazada por relaciones funcionales que generan propiedades emergentes como en un ser vivo y que, por lo tanto, poseen una historia evolutiva y en algún sentido teleológica.

\# El alcance moderno de la dualidad se hace patente recordando que fue precisamente esta oposición el problema central de Kant, quien trabajó afanosamente por la conciliación de una explicación mecánica de la naturaleza con la exigencia de nuevos conceptos para incorporar en el cuadro racional el orden de los géneros, especies e individuos que constituyen la multiplicidad fáctica de la naturaleza. Cf. Crítica del juicio.

* "El entendimiento humano hace uso del don precioso de la reflexión y esta luz primera es la aurora de una sabiduría benéfica, que, mejorando la parte más noble del hombre, lo coloca en el alto destino que lo separa de la naturaleza irracional." $\left(^{8}\right)$ El contraste puede ejemplificarse con un texto de "Decadencia y Restauración": "En él (cadáver) se conoce cuál es el enlace, y los oficios de los distintos órganos que componen esa máquina singular, la primera entre las obras de la Divinidad: en qué consiste la mutua dependencia con que se auxilian, o dañan unas a otras; cuáles son las verdaderas causas que fomentan o destruyen su armonía, y cuál es el modo de restaurarla" $\left({ }^{9}\right)$ y la cita de Linneo, hecha por Unanue en su "Disertación sobre la coca” $\left({ }^{10}\right)$, para referirse a la 'regla sólida' que conducirá sus inquisiciones: Systemate, qualitate, et experientia eruitur omnis usus plantarum (Mat. Med., Canon 14). 
En efecto, en el comportamiento cognoscitivo de la medicina, la botánica o la zoología modernas, gravitaban los conceptos de 'tipo', 'género', 'especie' y otros semejantes, de clara raigambre platónica, que ocupaban en lo que hoy llamamos ciencias biológicas el lugar que en el edificio de la cinemática geométrica de la física matemática mecanicista ocupaban la relación causal local, la hipótesis y la deducción *.

\section{El otro paradigma moderno de ciencia}

Pero la distinción que hemos realizado al objetar la caracterización de Unanue como un 'ilustrado mecanicista' o como un 'ecléctico' no implica inscribir su pensamiento en un contexto tradicional premoderno. El gran científico sueco Carl von Linneo (1707-1778) \& -fuente fundamental de Unanueilustraba con claridad la oposición existente en dicha época entre la mentalidad mecanicista y la históriconatural, como parte del debate moderno.

Linneo recuperó para la ciencia moderna los conceptos clásicos de género y especie, rechazados por los mecanicistas; pero, al naturalizarlos -por así decirlo-, imprimió un nuevo sentido no metafísico a su uso, para oponerlos al acentuado sentido instrumental o matemático-formal que tenía el método mecanicista de Galileo, Descartes y Newton. Unanue refleja en una misma época y en un mismo espíritu científico el entrecruzamiento de dos paradigmas en disputa desde el siglo XVII. Dualidad en el uso del concepto de razón: el de la 'razón físico-matemática' que se opone al de la 'razón histórico-natural'.

La opción epistemológica de Unanue en este debate moderno tampoco es un asunto personal. Si uno revisa la producción científica en el Perú entre los siglos XVII y XVIII en las áreas de física, matemática, astronomía y medicina (desde 'El conocimiento de los tiempos' hasta el Mercurio Peruano), la concepción mecanicista de la naturaleza no se muestra hegemónica en nuestra naciente comunidad científica de entonces ${ }^{\prime \prime}$. En la literatura científica peruana registrada se nota, más bien, una hegemonía del paradigma organicista de la naturaleza y una metodología ligada a las ciencias biológicas. Reveladora del paradigma que orienta la literatura médica de Unanue es la metáfora del organismo como 'máquina viviente' $\left.{ }^{(11}\right)$. Por otro lado, si bien la concepción mecanicista alcanzó a hegemonizar el mundo científico europeo hasta la esfera de la química inorgánica, tuvo una presencia secundaria en el desenvolvimiento de la medicina moderna, apenas visible durante el breve auge de la 'iatromecánica'.

En su "Discurso para el establecimiento de unas conferencias clínicas de Medicina" $\left({ }^{11}\right)^{9}$, Unanue anotaba que la exposición de la enfermedad debe dividirse en: (i) la historia de la enfermedad, (ii) la curación y (iii) las observaciones. La historia natural parece la forma fundamental de explicación en el conocimiento médico. Si bien acepta que en el campo de la anatomía la descripción y la determinación de las conexiones mecánicas son fundamentales, ellas finalmente dependen de la función que realizan los entes orgánicos que nacen, crecen, se desarrollan y mueren.

$\mathrm{Si}$ bien el paradigma organicista fue progresivamente derrotado a lo largo de los siglos XVII y XVIII por la concepción mecanicista al interior de las comunidades científicas de físicos y químicos no fue completamente desalojado de la totalidad de las disciplinas de la ciencia moderna. Por el contrario, este enfoque fue fundamental para los nuevos desarrollos que adquirirán las ciencias biológicas y las nuevas ciencias sociales de la segunda mitad del siglo XIX con Claude Bernard (1813-1893) y Johann

* Unanue, muy significativamente, empareja a Newton y Linneo, calificando a ambos como 'muy superiores al resto de los filósofos' $\left({ }^{2}\right)$. En el mismo sentido puede tomarse las líneas finales de la «Advertencia a la segunda edición» de sus Observaciones sobre el clima de Lima... $\left.{ }^{3-5}\right)$, en las que dice que "la narración filosófica, las imágenes y descripciones poéticas" de su texto, las hizo "teniendo por maestro a Platón" (p. 5).

$\$ \quad$ Padre de la Taxonomía científica moderna para nombrar, ordenar y clasificar los organismos vivos (cuyo sistema todavía se usa, aunque con muchos cambios), influenció a generaciones de biólogos mucho después de su muerte, incluyendo a aquellos que se oponían a las pretensiones filosóficas y teológicas de su trabajo, de una manera análoga a como posteriormente sucederá con Mendel en la genética.

I De hecho, desde la Sección I, titulada "Historia del clima", de sus Observaciones, contiene una minuciosa recopilación de la información científica acumulada sobre el Perú por la comunidad científica colonial y diversos viajeros científicos europeos desde inicios del siglo XVII, entre ellos: Juan Rer, Pedro Peralta, Cosme Bueno, Ulloa, Godin, Matías Porras, Humboldt, Gabriel Moreno, Bravo de Laguna, Vargas Machuca y otros.

` Citado por Augusto Salazar Bondy $\left({ }^{1}\right)$, p. 44. 
Gregor Mendel (1822-1884), así como con Aguste Comte (1798-1857) y Émile Durkheim (1858-1917), en el proceso de su independización epistemológica y metodológica creciente del paradigma mecanicista newtoniano como modelo único y absoluto de cientificidad moderna, paradigma que era considerado por lo menos inválido para lo que hoy denominamos como ciencias biológicas.

A diferencia del cosmos mecanicista, en el que sus átomos se encuentran separados por el vacío así como la subjetividad humana está separada del entorno natural (como condición de objetividad de sus observaciones), en el organicismo 'todo' se encuentra vinculado por relaciones funcionales de tipo orgánico, incluyendo al propio observador, como veremos más adelante en Humboldt, otra de las grandes influencias en el pensamiento de Unanue y de nuestra tradición científica nacional.

El conocimiento médico del individuo se fundaba, para Unanue, en la vinculación del organismo a su medio, dando lugar a lo que él caracteriza en términos disciplinarios como 'nuestra Medicina topográfica' **. El medio otorgaba su carácter peculiar al ser vivo y condicionaba su manera de relacionarse ante las excitaciones sensibles. Esta concepción del conocimiento, según patrones naturales sensibles, no vincula necesariamente a Unanue con el empirismo. Lo que pasa es que, en América, los científicos redoblaron el énfasis de la experiencia sensible a causa de la doble barrera que representaba la tradición católica y española y la cultura ágrafa imperante en la gran masa de la población. De ahí la apariencia de adhesión al 'empirismo' por parte de nuestras élites científicas iniciales, que ha originado numerosos equívocos.

\section{La naturaleza como organismo vivo}

Salazar ha mostrado con agudeza que, para Unanue, la naturaleza en su conjunto se presenta como un todo articulado y autogenerado: "lo que la

** Unanue $\left({ }^{3}\right)$, p. 151.

$\dagger \quad$ Salazar acompaña estas citas con las siguientes certeras referencias: "Introducción a la descripción de las plantas del Perú" $\left.{ }^{2}\right), p$. 74. En la "Disertación sobre el tabaco", alude a la opinión de que éste es "la yerba más privilegiada de cuantas abriga la naturaleza en su fecundo seno" $\left({ }^{14}\right)$. En el fragmento Fiestas linneanas, la imagen maternal se aplica a la tierra con idéntico sentido $\left({ }^{15}\right)$.

\# Unanue $\left(^{3}\right)$, pp. 16-17.
Naturaleza nos negó de tierras cultivables, nos lo reemplazó con inmensas cordilleras atravesadas por todas partes de vetas minerales" $\left.{ }^{(12}\right)$. La naturaleza es aquí descrita como una macroentidad que autorregula la distribución de los objetos naturales en un orden y equilibrio peculiar, análogo a un inmenso organismo vivo, y no de manera aleatoria como supone el atomismo mecanicista.

Las imágenes a que se echa mano para caracterizar este ser de la Naturaleza son, la mayoría de las veces, de orden biológico. Pero a dicha mirada tampoco se le puede atribuir el ser resultado de una simple transferencia del entorno cultural europeo a nuestro entorno cultural local. Ella daba una suerte de fundamento ideológico 'natural' a los afanes independentistas de 'los hijos de esta tierra', como se solía denominar en la época colonial al conglomerado de casta que iba desde los indígenas hasta los criollos.

En nuestros ideólogos separatistas, la naturaleza adquiere un aura 'maternal', una figura estéticamente aceptable al entorno cultural andino de una sociedad agraria dominada por relaciones de parentesco, en la que la expresión simbólica está atravesada por una sensibilidad desarrollada a partir de una dependencia afectiva de la tierra, completamente divergente con la mirada ajena del sujeto cosmopolita moderno, que la observa como un mero objeto externo de manipulación. La naturaleza es recurrentemente representada como una 'benéfica madre' que 'engendra, y diversifica sus producciones' $\left({ }^{13}\right)$, 'sustentadora de los mortales', en quien se admira el despliegue de 'toda la fuerza de su inagotable fecundidad' ${ }^{\dagger+}$.

La naturaleza no es vista como un frío e incoloro espacio lógico-matemático de conexiones causales atómicas, sino como una realidad en algún sentido más próxima a la spinoziana natura naturans, vinculada al hecho de la fuerza creadora que halla su más cálida y cruda expresión en la vida animal: "Los animales sienten (en la primavera) un estímulo más activo que los induce a la conservación de su especie, para que sobre los cadáveres de la naturaleza arruinada, que se hallan esparcidos por la tierra y las aguas, triunfe el amor, reproduciéndonos nuevos seres, que perpetúan los siglos de vida en la carrera del tiempo destructor”

La naturaleza es pensada como una fuerza benéfica que se ejerce en provecho de los seres creados de sí, pero sobre todo del hombre: "no insultemos a la naturaleza: ella es grande, sabia y hermosa en medio de sus ruinas; sin éstas, quedarían 
imperfectas sus obras y serían estériles nuestras especulaciones" $\left({ }^{16}\right)^{*}$.

\section{Una 'medicina topográfica'}

El poder de autocreación y autodesenvolvimiento que la naturaleza entraña para Unanue es una atmósfera ideológica en un cierto sentido afín con temas posiblemente heredados de la filosofía renacentista de la naturaleza, con la posición de un macroorganismo universal y de un principio inmanente y divino. En las 'Observaciones', refiriéndose a las edades en que la Tierra no estaba aún habitada, dice: "Solo aparece la Naturaleza rodeada de un silencio misterioso. Su mano poderosa va a dar la última perfección al Globo y sostener su equilibrio fabricando dos mundos distintos en un solo continente" $\pitchfork$.

En los debates naturalistas que desembocan finalmente en el siglo XVIII, esta mirada encontró un símbolo científico en Linneo, el más inspirado intérprete de esa animación cósmica. Esta inmersión del cuerpo en la vida universal se puede ver en buena parte de "Observaciones sobre el clima de Lima y su influencia en los seres organizados". Lo que decide la marcha de las funciones corporales engarza en el funcionamiento del organismo con su medio topográfico, sometiéndolo a un complejo de mutaciones que es imposible prever y controlar si no se atiende a la marcha del organismo universal: "En continuo choque, las partes que componen el edificio de nuestra mortalidad, sometidas a la acción de los elementos que las vivifican, es imposible precaver las consecuencias del movimiento y evitar los debates y alteraciones de los cuerpos que nos rodean. Éstas están íntimamente conexas con el sistema del Universo".
Si bien esta mirada no resulta necesariamente antagónica con la explicación causal de la física mecanicista, por cierto la desborda hacia una comprensión de tipo providencialista de la historia natural, completamente ajena al relativismo mecanicista galileano. Un finalismo que, aunque se manifiesta en explicaciones secundarias y no remite directamente a un único final de tipo profético o teológico, desborda el 'sistema del mundo' cartesiano o los 'principios matemáticos de la filosofía natural' newtoniana, donde no existen finalidades, números ni lugares privilegiados en el espacio infinito.

Un ejemplo de ello se muestra en la explicación que hace Unanue de los movimientos sísmicos: "No están... 'destinados' únicamente a la desolación del globo; prescindiendo de los bienes que suelen procurar en todas partes, ordenan en Lima la constitución del tiempo" $¥$, o el de la humedad de la tierra que "es evaporada para que no se pudran los pastos" \&. "La divina providencia, que ha proporcionado a sus criaturas racionales en todas las partes del globo los medios para subsistir y cumplir los trabajos a que los destinaba, dio al indio habitante de los Andes un don precioso en los pastos" "I.

El hombre es presentado como el punto culminante de la historia natural, hacia cuya conservación y prosperidad convergen todos los demás objetos de su entorno natural: "Todos los vegetables, desde el humilde musgo hasta el coposo y soberbio cedro, están destinados al servicio del hombre, monarca de la naturaleza. Los unos lo sustentan, los otros lo visten; otros reparan su salud y todos juntos elevan su espíritu a rendir el homenaje de gratitud y sumisión debido al Autor Supremo que viste de pompa y fragancia las campiñas" ".

* Una idea que, por lo demás, ha sido muy empleada, según Salazar, en las explicaciones de la Teodicea. Dice, en la «Introducción a la descripción de las plantas del Perú», que existe en las montañas de los Andes del Perú, "aquel rico tesoro de las preciosidades de la Naturaleza, donde esta madre benigna y sustentadora de los mortales ha desplegado toda la fuerza de su inagotable fecundidad" $\left({ }^{2}\right)$, p. 74. En su "Disertación sobre el tabaco" dice: "Nada puede instruir al hombre de la índole de las plantas como sus propios sentidos. Para esto los ha colocado en él la benéfica naturaleza" $\left({ }^{14}\right)$, p. 38. En "Geografía física del Perú", habla de la naturaleza como de "nuestra madre y liberal benefactora" ( $\left.{ }^{16}\right)$, p. 11. Cf. Asimismo, Unanue $\left({ }^{3}\right), p .180$.

$\dagger \quad$ El capítulo I de la sección IV de las Observaciones..., tiene por título: "De la autocracia o poder que la naturaleza sostenida por la dieta tiene en la curación de las enfermedades", ( $\left.{ }^{3}\right)$, p. 180.

Unanue $\left({ }^{3}\right), p .43$.

$\S \quad$ Ibid, p. 21. En la "Noticia de los trajes" $\left({ }^{17}\right)$, p. 87, nota 31, dice que en los usos militares se fuerza al hierro y al fuego a que "sirvan contra sus destinos".

1 Unanue $\left({ }^{3}\right)$, p. 62.

\Unanue $\left({ }^{18}\right)$. La expresión «Rey de la Naturaleza» está presente también en "Decadencia y restauración... ”. Mercurio Peruano. $N .{ }^{\circ} 219, p .92$. Y la orientación final, referida expresa o tácitamente al hombre, se transparenta asimismo en aquellos textos que hemos usado al hablar de la concepción de la naturaleza como madre benéfica, etcétera. 
A la Providencia, hemos de referir también la interna constitución armoniosa de cada ente orgánico y en especial del cuerpo humano, así como su ajuste con el ambiente que lo rodea que ayudan a la humanidad a sobrevivir y a prosperar: "Ni podemos menos de agradecer a la mano liberal y cuidadosa de la Providencia -dice Unanue a propósito de las fiebres palúdicas- que, para impedir la despoblación de estos países colocase el remedio al frente del mal, con tal exactitud, que a la misma línea que siguen las tercianas invadiendo las provincias del bajo Perú, camina otra paralela por los Andes productiva de las cascarillas"**.

Una consecuencia importante del paradigma organicista reside en el modo como integra el mundo natural y social frente a la rígida separación simbólica impuesta por la cultura científica mecanicista moderna entre dos reinos: la naturaleza cosificada y regida por la causalidad, separada de la sociedad humana regida por la libertad moral de sus individuos. El dualismo filosófico moderno fue consagrado por Descartes en su doctrina de las dos sustancias (res extensa y res pensante) y por Galileo en su doctrina de las 'dos verdades' (verdades de fide y verdades demostrativas), ejemplificada en su famosa sentencia: "la Religión, nos enseña 'como se va al cielo', la Física, solamente 'como va el cielo'”.

\section{El neoplatonismo científico renacentista}

La interpretación organicista -al igual que la mecanicista- no era de raigambre exclusivamente moderna; era de raíz neoplatónica y solo en algunos aspectos aristotélica. La cosmología platónica resaltaba el papel central del sol y del fuego, junto con los pitagóricos y estoicos y con una tradición médica que también los consideraba principio de vida y fuerza natural originaria. Esta tradición tiene su origen en los supuestos escritos herméticos atribuidos a Hermes Trismegisto (s. II a. C) y al movimiento místico y filosófico conocido como 'neoplatonismo', fundado por Plotino (205-270) y continuado por Porfirio (232-303) y por Proclo (412-485).

Las ideas neoplatónicas estuvieron presentes durante la Edad Media a través de Boecio (480-524) y sobre todo de San Agustín (354-430). De este último se derivaron dos líneas; una de ellas lleva a la

** $\quad$ Unanue $\left({ }^{3}\right)$, pp. 254-255. contemplación de mundos inteligibles fuera de la realidad física. La segunda línea, ligada a la interpretación cristiana del Timeo, es la que llevó a la contemplación del mundo físico producido por el plan creador de Dios.

El descubrimiento del Nuevo Mundo condujo a una reconsideración de los viejos sistemas de comprensión heredados de la tradición aristotélicotomista, pues sus descripciones de los elementos naturales simples y mixtos no correspondían con sus recientes observaciones del mundo americano. Los grandes relatos elaborados por los jesuitas José de Acosta (Historia natural y moral de las Indias, 1590), Bernabé Cobo (Historia del Nuevo Mundo, 1653), J. E. Nieremberg (Historia naturae maxime peregrinae, 1635), Antonio Vieira (História do Futuro, 1650) y S. De Vasconcellos (Notícias curiosas e necessarias das cousas do Brasil, 1668) son ejemplos paradigmáticos de esta lectura. Este sistema fue dominante en las universidades europeas durante el periodo 1500-1650. Entre sus precursores hay filósofos y místicos como Agripa, Wiegel y Jacob Böhme; científicos como Paracelso (1493-1541), Kepler (15711630) y Johann Baptista van Helmont (1578-1644).

Para el neoplatonismo la materia era el vínculo unitivo con el mundo del espíritu y ello lo llevó a jugar un papel decisivo en el surgimiento de la modernidad. Causó gran impacto en el mundo intelectual renacentista del siglo XVI como puede observarse en la Utopía de Tomás Moro, en la obra de Pico de la Mirándola y de Giordano Bruno. En el siglo XVII su influjo alcanzó a los platónicos de Cambridge.

\section{La 'segunda escolástica' jesuita}

Pero los orígenes propiamente modernos de la lectura organicista provienen de la literatura científica de la llamada 'segunda escolástica' que tomó distancia de la tradición aristotélica. Ésta fue promovida por los jesuitas, a partir de la contrarreforma católica iniciada en el Concilio de Trento (1542-1562). Desde el Colegio Romano los jesuitas intervinieron con una versión propia en el debate renacentista y barroco de la revolución científica de los siglos XVI y XVII, como los grandes adversarios del mecanicismo de Galileo y Newton.

El Colegio Romano organizó las llamadas 'redes jesuíticas' de información de lo que podríamos denominar como la versión católica moderna de la realidad natural y social, que trataba de empatar la 
filosofía y teología cristiana tradicionales con las nuevas propuestas científicas modernas. Mucha de la información empírica de la ciencia organicista de la naturaleza provenía de los testimonios que los misioneros científicos jesuitas enviaban regularmente a Roma desde todo el mundo. Son particularmente famosos los de los jesuitas Martín Martini, 'Atlante Chino'; de Baltasar d'Anglada, misionero en el Tíbet y del padre José de Acosta desde el Perú ${ }^{\dagger}$. El propio cronista indígena Guaman Poma registra numerosas evidencias de esta influencia jesuita

Un impulso decisivo a la cosmovisión organicista vino posiblemente con el descubrimiento de la circulación de la sangre por William Harvey (De motu cordis, 1629), que ejerció una gran influencia en las ideas de los primeros geólogos, quienes concebían la Tierra como un cuerpo vivo con su circulación de agua. Precisamente Hutton, considerado el 'padre' de la Geología moderna, había estudiado medicina e hizo su tesis sobre la circulación de la sangre.

La idea central de esta concepción, sustentada por la monumental obra del padre Athanasius Kircher (1601-1680), líder de los científicos jesuitas, era que la Tierra constituía un vasto organismo vivo (el macrocosmos) con una osamenta pétrea formada por las cordilleras montañosas, un núcleo central de fuego y grandes cavidades subterráneas por las que circula el fuego (los 'pirofilacios'), otras por las que fluye el agua (los 'hidrofilacios'), y otras por las que el viento sopla (los 'aerofilacios'). En estos textos es muy difícil separar los elementos teológicos de los experimentales modernos, pues hay una gran concordancia entre ambos *.
A inicios del siglo XVII la ciencia jesuita logró un considerable prestigio en los medios modernos, en parte por contradecir constantemente opiniones secundarias de las grandes autoridades de la antigüedad aristotélica y escolástica, logrando brillantes correcciones a tal tradición, lo que contribuyó no poco a su impopularidad entre el resto del clero tradicional. En el contexto del nacimiento de la ciencia moderna, el organicismo ocupó una suerte de posición intermedia entre el mecanicismo y el vitalismo mágico, sirviéndose de analogías tomadas del mundo que hoy llamamos biológico. El lenguaje que utiliza tuvo posiblemente su origen en la observación del cambio por crecimiento y decadencia en diversos fenómenos naturales. Pero también postuló la existencia de una suerte de estructura orgánica estable que da sentido al cambio.

La filosofía neoplatónica tuvo una gran influencia en el mundo hispánico desde el Renacimiento. Autores como León Hebreo ${ }^{\dagger}$ o Juan de Valdés (1500-1541) se insertan en esta tradición. El primero marcó una decisiva influencia neoplatónica en la construcción narrativa del mundo andino por Garcilaso de la Vega, ampliamente mostrada por los ya clásicos trabajos de José Durand * y Mariano Iberico ${ }^{\S}$. Por otro lado, la idea -de gran fuerza simbólica en esta tradición- de la circulación de la sangre ya estaba en el español Miguel Servet (1511-1553) mucho antes que William Harvey II. Son igualmente documentadas las influencias del líder de los científicos jesuitas Atanasio Kircher sobre los filósofos, teólogos y naturalistas hispanos ^. Durante el siglo XVII, la línea platonizante

${ }^{\dagger \dagger}$ Cf.: Sequeiros $\left({ }^{19}\right)$. Ver también: "El Geocosmos teológico de Athanasius Kircher (1601-1680)". Proyección, Granada, 2000, XLVII, 199, pp. 281-300. Igualmente: “Athanasius Kircher (1601-1680), el geólogo que creía que la Tierra estaba viva”. ACMIPA, Córdoba, 2001, 43, pp. 22-23.

\$asta ver los términos elogiosos con que se refiere a los jesuitas en el volumen 2 de la edición citada $\left({ }^{20}\right):$ "Después que ha entrado esta orden en este reino, ha entrado el Dios del cielo en el mundo de este reino» [fol. 636] y en particular al padre Acosta, de quien afirma haber leído su De Procuranda Indorum salute [fols. 1078-1080]. Abunda a favor de nuestra opinión, entre otras cosas, la observación hecha por Franklin Pease $\left({ }^{21}\right)$, según la cual en la mirada que Guaman Poma realiza de la naturaleza «la imagen del mundo consistía en una geografía sagrada”.

Cf. Capel $\left({ }^{22,23}\right)$.

† León Hebreo (Yehuda Abrabanel) nació en Lisboa en una fecha desconocida. Fue un extraordinario intérprete del neoplatonismo renacentista. Renovó la erótica de Platón buscando armonizarla con otras tradiciones: el realismo peripatético, la teología y la mística judaicas. En 1535, cuando seguramente ya había muerto, se publicó en Roma su obra maestra en italiano florentino: Diálogos de Amor.

\# Durand $\left({ }^{24}\right)$. Ver: cap. II, “Garcilaso el Inca, platónico”, pp. 22-30.

$\$$ Iberico $\left({ }^{25}\right)$.

II Su obra Exercitatio Anatomica de Motu Cordis et Sanguinis in Animalibus (Ensayo anatómico sobre el movimiento del corazón y la sangre en los animales) fue publicada en 1628.

1 Particularmente de su obra más importante: Kircher $\left({ }^{26}\right)$. 
y hermético-alquímica estuvo presente hasta en un texto de naturaleza técnica como 'El arte de los metales' (1640) de Alonso Barba, escrito en Potosí. Esta línea neoplatónica fue predominante en casi todas las grandes obras de los naturalistas jesuitas y cosmógrafos coloniales que antecedieron a Unanue, profusamente citados en sus Observaciones.

\section{La tercera ola organicista}

Los finales del siglo XVII coinciden con el inicio del declive del organicismo jesuita en favor del mecanicismo ilustrado, pero nuevamente volverá a aparecer como movimiento antiilustrado en la 'Naturphilosopische' de los médicos naturalistas y filósofos románticos alemanes de fines del siglo XVIII e inicios del siglo XIX y a fines del mismo siglo en los médicos y filósofos vitalistas franceses, como Claude Bernard (1813-1893) y H. Bergson (18591941).

El contexto de las décadas finales del siglo XVIII y las iniciales del siglo XIX marca el fin de los grandes viajes descubridores que se desarrollaron a lo largo de los siglos XVI y XVII. Los viajes de aventura comienzan a ser sustituidos por los viajes de recapitulación científica de lo conocido; se inicia la fiebre del inventario, la recapitulación y clasificación del saber adquirido de forma salvaje. El aventurero, el conquistador y el político ambicioso pasan a ser sustituidos por el viajero científico romántico que se replantea la mirada en conjunto de lo ya descubierto.

Nacen las ciencias de la Tierra. El laboratorio y el museo aparecen como las instituciones centrales para la clasificación y el inventario completo. Se desarrolla la estratigrafía para medir las edades de la Tierra y la arqueología para medir las edades del hombre. Aparece el Jardín Botánico como modelo de laboratorio viviente para medir las épocas de la naturaleza. La historia desacralizada se vuelve natural y la naturaleza des-mecanizada se vuelve histórica.

Estos naturalistas románticos son críticos furibundos de la concepción mecanicista de la naturaleza y del entendimiento conceptualista del saber, sobre los que se funda la ciencia moderna de Descartes y Newton. A ella van a oponer el entendimiento de la naturaleza como un sistema orgánico de fuerzas o energías activas análogas a la voluntad humana, capaces de generar propiedades emergentes, variaciones y evoluciones internamente funcionales al sistema autónomo al que pertenecen, resultando una naturaleza completamente diferente a la naturaleza invariante del mecanicismo. Su entorno intelectual es una filosofía poskantiana crítica del intelectualismo ilustrado.

El afán común de los naturalistas románticos por privilegiar la sensibilidad sobre la teoría se basó en una comprensión naturalista del conocimiento como una función biológica y no ideológica, como la concibió la ilustración. Su rechazo al dualismo moderno se expresó en el proyecto central de construir una 'filosofía natural' que emergiera no de principios matemáticos sino de una 'historia natural universal'.

\section{La historia natural universal de buffon}

A fines del siglo XVIII (1788) muere en Francia Gorges Louis Leclerc, Comte de Buffon, exponente supremo de las ciencias biológicas europeas hasta la revolución francesa. Él había sido, desde 1739, director del 'Jardín del Rey', el más célebre laboratorio botánico experimental de Europa. Su obra magna 'Historia natural, general y particular' fue publicada en 44 volúmenes, entre 1761 y 1809, y pretendió dar el panorama más completo de la historia natural del mundo. Tal obra convirtió a Buffon en el Newton de las ciencias biológicas y en el científico más influyente y leído del siglo XVIII.

Buffon basó su explicación del proceso de diferenciación de las especies botánicas y animales en un mecanismo básico y universal: el enfriamiento gradual de la Tierra desde los polos. Todas las diferenciaciones existentes en la naturaleza fueron presentadas en un continuum de graduaciones, rechazando la teoría de la existencia de diferencias cualitativas de tipos o especies fijas. En segundo lugar, explicó la distribución diversa y grupal de los diferenciados como resultado de las migraciones de los animales de mayor tamaño a las zonas tropicales boscosas por requerimientos alimenticios. En tercer lugar, correlacionó las variaciones en el tono de la pigmentación de la piel con las variaciones climáticas, de manera que las pieles más blancas se acercaban a los polos y las más oscuras al trópico.

La teoría de Buffon se fundamentaba en un inmenso arsenal de información empírica y en toda una orientación epistemológica divergente con el mecanicismo acerca de los métodos adecuados de 
observación, descripción y clasificación científica de los fenómenos biológicos. El primer paso en la descripción (de un individuo o especie) biológica consiste en capturar el conjunto (ensamble). En segundo lugar, distinguir analíticamente sus partes estableciendo las diferenciaciones (individuales o específicas) del organismo en cuestión en comparación con sus análogos, de manera que nos debe quedar un remanente que constituye su 'esencia', 'centro' o estructura invariante.

\section{Otra vez, la refutación está en América}

No obstante, Buffon encontró en América por lo menos cuatro contraejemplos devastadores de su teoría. En primer lugar, no se había establecido la existencia originaria de hombres negros en las zonas tropicales americanas. En segundo lugar, la presencia autóctona de pueblos de piel oscura en las regiones polares de América como Alaska. En tercer lugar, en el trópico americano no se había encontrado ninguna especie similar o análoga al elefante o la jirafa. En cuarto lugar, se presentaba numerosa evidencia de la existencia actual de grandes mamíferos exclusivamente en América del Norte. El propio Thomas Jefferson envió burlonamente a Buffon una cabeza de alce que refutaba sus teorías.

Buffon, apelando a un procedimiento frecuente en la historia de la ciencia, elaboró dos hipótesis $a d$ hoc o explicaciones excepcionales. Una primera que denominó 'excepcionalismo americano', según la cual, el proceso migratorio norte-sur se interrumpió en el istmo de Panamá, imposibilitado de atravesarlo. De ahí que América del Sur sólo produjo animales pequeños y débiles. No muy distinta fue la situación de los hombres (incluidos los migrantes europeos luego de la conquista), que progresivamente se fueron debilitando y empequeñecieron.

Pero como toda hipótesis ad hoc, la de Buffon resultaba inconsistente con el resto de la teoría. Si la población de América del Sur no era de origen norteño y si el tamaño y la fuerza en las variaciones de las especies era explicado por el determinismo climático, ¿cómo explicar su debilidad y pequeñez siendo de origen tropical? Había que desarrollar entonces alguna explicación igualmente $a d$ hoc sobre el 'empequeñecimiento' de dichas poblaciones originarias ${ }^{* *}$. Ello condujo a una nueva hipótesis, que se suele hoy designar con el nombre de 'hipótesis arriesgada' o 'negativa', la que consiste en postular la existencia de alguna entidad inobservable, como las 'entelequias' o 'causas ocultas' aristotélicas. Es decir, se trata de hipótesis que no se infieren de la teoría ni se inducen de la observación. En realidad, son como parches ante una ausencia de explicación.

En efecto, Buffon elaboró una suerte de teoría excepcional de la 'generación' según la cual en estas zonas tropicales americanas, por la combinación especial de la temperatura y la humedad del clima, se presentó una peculiar escasez de ciertas 'moléculas orgánicas' decisivas para la alimentación. Y como la forma de vida está, según su teoría, determinada por la interacción causal entre el embrión del organismo y las partículas orgánicas que requiere asimilar por alimentación para su desarrollo, se produjo una involución.

Por supuesto, tales 'partículas orgánicas' nunca fueron identificadas, sino solo supuestas, para poder explicar la 'excepción'. Pero nuevamente emergió otra dificultad, pues, si se trató de una situación contingente ('escasez'), las dificultades resultaban mayores para la teoría de Buffon. ¿Cómo daba cuenta de la invariancia total en la involución sólo por la ausencia de un factor causal de la evolución? ¿Habría que suponer entonces la existencia de algún patrón o fuerza causal interna (herencia)? Pero, la teoría sólo admitía causalidades externas del entorno climático o alimentario. En otras palabras, las variaciones específicas resultaban mayores a las explicables por los cambios climáticos o alimentarios externos. Tal es el contexto científico en el que se desenvolvió la obra magna de Hipólito Unanue "Observaciones sobre el clima de Lima y su influencia en los seres organizados, en especial el hombre".

** En realidad, la tesis del 'empequeñecimiento' no era original de Buffon. A finales del siglo XVI (1572), el cosmógrafo oficial del Consejo de Indias, Juan López de Velasco, describía este mismo medio natural como causa de la degeneración de los propios españoles que se afincaban en América: "Los que allá nacen de ellos que llaman criollos... conocidamente salen ya diferenciados en la color y tamaño porque son grandes y la color algo baja, declinando a la disposición de la tierra", más aún, "no solamente en las calidades corporales se mudan, las del ánimo suelen seguir las del cuerpo y mudando él, se alteran también” $\left({ }^{27}\right)$, pp.27 y 37-38. 


\section{La (historia) 'fisiognomía regional' de Humboldt}

Aunque Humboldt compartirá todavía con Buffon la relevancia del componente territorial (climat) como causa de las diferenciaciones biológicas, no compartirá una comprensión 'externalista' del entorno territorial. Por el contrario, sus estu dios empíricos enfatizarán las características irreductibles de cada 'región territorial', comprendiendo cada una de ellas como un 'todo orgánico observable' al que denominará 'fisiognomía de la región'. Con Humboldt desaparece la noción buffoniana de 'centro' o 'esencia' invariante, de naturaleza inobservable. Es decir, cada región es considerada como si fuera un ser orgánico distinto, en donde los seres orgánicos menores que contiene son entendidos como componentes funcionales de lo que hoy llamaríamos un ecosistema.

De ahí que, para Humboldt, no se trata de buscar una ley universal de invariancia de la naturaleza, sino precisamente una ley regional interna de la variación -en el mismo sentido que orientarán la investigación biológica Darwin y Mendel- o, mejor dicho, de los componentes funcionales de los organismos, desde los individuos hasta lo que hoy llamaríamos ecosistemas o macroorganismos regionales.

Esta visión organicista de la naturaleza constituyó en el siglo XIX la carta de ciudadanía de la autonomía científica de la biología. De hecho, para Humboldt, la descripción fisiognómica de una región -a diferencia de Buffon- no debía partir de la descripción primaria de los factores geológicos sino de la composición de su vida orgánica (plantas, animales, hombres) o seres vivos: "De la misma manera como reconocemos una determinada fisiognomía en seres orgánicos distintos, así también podemos reconocer en cada región de la tierra una fisiognomía natural que le es peculiar". Ellos constituían -en ese ordenel 'dato fundamental' de la fisiognomía regional: "la capa vegetal que adorna a todo el planeta es el principal elemento de la observación" ${ }^{\dagger \dagger}$.

Las plantas -que son para Humboldt el indicador más estable de un todo orgánico- se encuentran funcionalmente ligadas al contexto climático y su clasificación resulta imposible fuera de su contexto -en un jardín botánico-, como hasta entonces se venía haciendo, pues no eran universales ya que no existía en la tierra un contexto homogéneo. Para Humboldt,

$\dagger \quad$ Humboldt $\left({ }^{28}\right)$, pp. 234 y 236. las clasificaciones botánicas sólo eran posibles al interior de lo que llamaba un 'tipo integral de paisaje', que era la verdadera 'unidad de observación', y ello sólo era posible in situ.

Las sesenta y nueve láminas que incluye en sus informes de viaje por América están diseñadas siempre de manera que hacen evidente la importancia de la comprensión unitaria del paisaje. Dichas láminas -en vísperas de la invención y uso científico de la fotografía- muestran con toda claridad la mirada romántica de la naturaleza de los científicos de comienzos del siglo XIX. En estas imagenes se combinan la visión idílica de los nativos americanos con el registro objetivo que realiza el científico observador europeo. En todas ellas los nativos aparecen desnudos y plenamente integrados al paisaje, como parte de la naturaleza. Los europeos, en cambio, siempre aparecen al margen del paisaje como observadores y anotadores testimoniales objetivos. Están in situ, pero no son parte del paisaje. Figura 1.

La 'mirada romántica' no quiere decir, sin embargo, el abandono de los métodos cuantitativos por parte de los científicos románticos. Lo que sucede es simplemente que el 'todo orgánico observable' no se reduce al registro analítico de sus partes, sino que está establecido por el conjunto de correlaciones que constituye la 'unidad de observación'. Como reza el célebre apotegma biológico: "dado un órgano, identificar sus funciones correspondientes”.

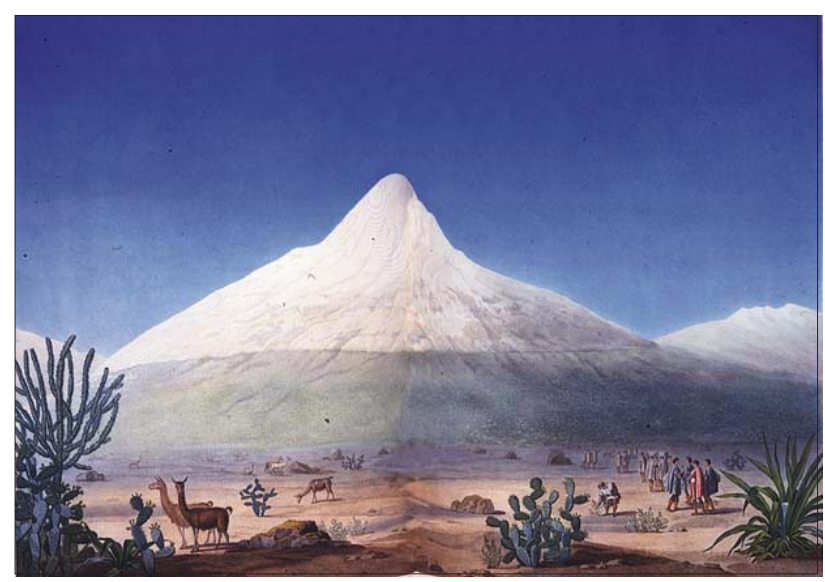

Figura 1. Imagen del Chimborazo en una de las láminas que ilustran los informes de viaje de Humbolt y que muestra la mirada romántica caracterizada por una visión comprehensiva del conjunto de correlaciones que constituye la unidad de observación. 
No obstante, el componente genético y el componente cultural parecían resistirse casi por completo a integrarse funcionalmente a la mirada naturalista orgánica fisiognómica de Humboldt. La genética y las ciencias sociales tendrán que disputar su propia carta de ciudadanía científica en el periodo siguiente de la historia de la ciencia contemporánea. Ellas requerirán un nuevo cambio en la mirada científica que se operará a lo largo del siglo XX, de la misma o quizá de mayor magnitud que la que enfrentaron los científicos decimonónicos.

El propio Humboldt no dejó de sorprenderse una y otra vez por la inmensa dificultad que tenía para encajar en sus esquemas físiognómicos la escasa diferenciación racial y social que encontraba en los nativos americanos, pese a las grandes variaciones 'altitudinales' (diversidad de pisos ecológicos) que existían entre sus diferentes poblaciones. Los componentes genéticos y/o culturales parecían desbordar toda simetría con su ecología regional. Pero este debate y sus desenlaces fueron procesos muy posteriores al contexto del debate científico que rodeó a Unanue.

La aparición de las 'Observaciones' de Unanue originó una gran sorpresa al barón de Humboldt, llevándolo a afirmar que era "un excelente tratado de fisiología". Sorpresa claramente expresada por uno de los comentaristas de la edición española de dicha obra, al señalar que era "en verdad muy extraño que llevando nosotros a los peruanos muchos siglos adelantados en la ilustración y bastantes años en la erección de cátedras de todas clases, se haya publicado el primer libro de esta clase en Lima, y no en Madrid" $"$

\section{Acosta, Kircher, buffon}

¿Cuál era la fuente principal de la coincidencia entre Humboldt y Unanue? Es posible que dicha coincidencia sea algo más que un asunto ocasional y se remonte a la genealogía organicista de la tradición científica moderna en el Perú desde el siglo XVI. Una evidencia textual de ello se encuentra en la profusa citación y en la común admiración de Unanue y Humboldt por la obra del padre jesuita José de Acosta (1539-1600), a quien Humboldt llamó 'el Plinio del Nuevo Mundo'.

En sus estudios sobre el Perú, Humboldt se encontró con la obra de Acosta y las de otros dos grandes naturalistas del siglo XVII: el jesuita Bernabé Cobo (Historia del Nuevo Mundo, 1653) ${ }^{*}$ y el cura de Potosí Álvaro Alonso Barba (El Arte de los Metales, 1640). A la vista están las numerosas referencias que hace Humboldt a los escritos de estos cronistas, sobre todo, en tres de sus obras: Vues del Cordillères et monuments des peuples indigènes de l'Amérique (París, 1810-13); Cristóbal Colón y el descubrimiento de América y, finalmente, Kosmos (Stuttgart/Tubinga, 1845-62, 5 vols) ${ }^{\dagger}$.

En Vues de Cordillères, Humboldt utiliza a Acosta * como referencia bibliográfica y como autoridad científica: "Ya Valdés y Acosta, primeros religiosos que visitaron América, dijeron que las pinturas aztecas 'eran escrituras semejante á la de los Egipcios' (...)". Para referirse al contenido de la obra de Acosta, Humboldt utiliza el mismo término - 'geografía física'- que emplea para su propia labor: “... el P. Acosta, más instruido que Garcilaso... compuso los primeros libros de su Geografía Física del nuevo continente en el Perú mismo, a fines del siglo XVI (...)".

Unos años más tarde, en su Examen critique de l'histoire de la géographie du Nouveau Continent, 1836-1839, Humboldt ${ }^{\S}$ escribe sobre los antecedentes de sus ideas: "Cuando se estudia a los primeros historiadores de la conquista y se compara sus obras, sobre todo las de Acosta, de Oviedo y de Barba, con las investigaciones de los viajeros modernos, sorprende encontrar el germen de las más importantes

Cit. por H. Unanue en: “Advertencia a la segunda edición” $\left({ }^{5}\right)$.

Suele atribuirse a Alexander von Humboldt la primera descripción de los pisos de vegetación en los Andes, a principios del siglo XIX, pero en realidad el jesuita Bernabé Cobo se ocupó de ellos casi dos siglos antes. Éste sostuvo que la mejor manera de entender los 'temples', 'grados' o 'andenes' de los Andes es mediante la descripción del ambiente en el que se desarrolla su vegetación y especies animales. Su relato es por ello una descripción fitogeográfica y zoogeográfica de las especies de cada piso ecológico, explicando así la presencia de diferentes plantas, animales y hasta asentamientos humanos en relación con la altitud y el clima.

Humboldt $\left({ }^{30-32}\right)$.

Valdés ( $\left.{ }^{33}\right)$, lib. II, p. 93 y Acosta $\left({ }^{34}\right)$, lib. VI, c. VII.

En: Parte 1 de Voyage aux régions equinocciales ... $\left({ }^{35}\right)$. 
verdades físicas en los escritores españoles del decimosexto siglo" "I. En Cosmos, Humboldt vuelve a hacer referencia al mérito de Acosta por ser el primero no solo en observar y describir los hechos, sino en llegar a deducir generalizaciones: "Desde la descripción del Nuevo Continente, discretamente bosquejada por el jesuita José de Acosta (Historia Natural y Moral de las Indias, 1590), no habían sido consideradas de una manera tan general las cuestiones que se relacionan con la física del globo" ".

Numerosas referencias a Acosta se encuentran en el capítulo dedicado al 'Desarrollo de la idea del cosmos en los siglos XV y XVI' (segundo tomo), donde destaca los vínculos entre su modelo de geografía física y de historia natural: "El fundamento de lo que hoy se llama Física del globo, prescindiendo de las consideraciones matemáticas, se halla contenido en la obra del jesuita José Acosta, titulada Historia natural y moral de las Indias (...)"**.

Pero Humboldt no se limita a citar a Acosta; sigue una misma manera de concebir la ciencia, tanto en el manejo taxonómico como en la interpretación holística de su 'geografía física'. Es común una concepción filosófica orgánica y funcionalista de la naturaleza y de las culturas humanas para comprender sus variaciones a lo largo del tiempo. La naturaleza se muestra como un todo integrado por seres de distintos reinos, pero conectado en una cadena vital. Su concepción de la naturaleza incluye minerales, plantas, animales y seres humanos como miembros de una misma y continua 'escala natural'. La historia natural y moral son integradas y ordenadas funcionalmente con respecto al todo.

El espíritu holista -adverso al procedimiento analítico de la ciencia mecánica- permite convertir el método comparativo en un procedimiento de síntesis. Siempre se busca establecer la unidad y armonía de la naturaleza en sus diferentes partes, la jerarquía de las inferiores a las superiores, desde los minerales hasta el hombre, y su integración en el cosmos como un todo. El cosmos se presenta así ante nuestros ojos como un inmenso organismo vivo.

Al igual que en la 'Historia natural y moral' de Acosta: "Los metales son como plantas encubiertas

11 Ibid., cit. por Sandra Rebok ${ }^{(36)}$.

1 Ibid., Humboldt ( ${ }^{32}$ ), I: 356 (nota de pie 25 de la página 51).

** Ibid., Humboldt ( $\left.{ }^{32}\right)$, II: 255 ss.

${ }^{\dagger}$ Acosta ${ }^{(34)}$, lib. IV, cap. 1, pp. 88-89. en las entrañas de la tierra, y tienen alguna semejanza en el modo de producirse, pues se ven también en sus ramos y como tronco de donde salen [...] y en alguna manera parece que crecen los minerales al modo de plantas [...] porque de tal modo se producen en las entrañas de la tierra por virtud y eficacia de sol y de los otros planetas, que por discurso de tiempo largo se van acreditando y cuasi propagando. $\mathrm{Y}$ así como los metales son como plantas ocultas de la tierra, así también podemos decir que las plantas son como animales fijos en un lugar, cuya vida se gobierna del alimento que la naturaleza les provee en su propio nacimiento. Mas, los animales exceden a las plantas, que como tienen ser más perfecto tienen la necesidad de alimento también más perfecto, y para buscarle les dio la naturaleza movimiento, y para conocerle y descubrirle, sentido. De suerte que la tierra estéril y ruda es como materia y alimento de los metales; la tierra fértil y de más sazón es materia y alimento de plantas; las mismas plantas son alimento de animales, y las plantas y animales alimento de los hombres: sirviendo siempre la naturaleza inferior para sustento de la superior, y la menos perfecta subordinándose a la más perfecta". ${ }^{\dagger}$

De manera análoga, para Humboldt su concepto de la 'física de globo' incluye el estudio del hombre en su función dentro de la naturaleza. La idea de una fuerte interconexión entre hombre y medio ambiente como un sistema armónico -hombre y naturaleza son vistos como opuestos en la tradición mecanicista moderna- es contraria al carácter problemático que esta relación tiene en el siglo XVIII para los filósofos ilustrados.

Athanasius Kircher, el líder científico de los jesuitas a lo largo del siglo XVII (nació un año después del fallecimiento de Acosta), quien cita a Acosta en diversos pasajes de su obra magna Mundus Subterraneus $\left({ }^{26}\right)$ y también en El Arca de Noe $\left({ }^{37}\right)$, constituyó la continuidad y expansión de esta tradición organicista jesuita. En su obra, el mundo aparece como "Un órgano verdaderamente armónico en número, peso y medida, por plan de Dios trino y providentísimo así dispuesto y adaptado, que aunque en los más íntimos escondrijos y lugares ocultos tenga instrumentos recónditos para su operación, sin embargo, por conductos subterráneos y por una inmensa multitud de tubos y fístulas hace oír la modulación de sus sonidos y tanta variedad de las más diversas voces, que es evidente que no hay nada en todo el mundo sublunar que no esté imbuido por 
su armonía simpática y por su número, peso y medida”

Al igual que en la 'Historia Natural' de Acosta, uno de los problemas que se plantea 'El Arca de Noé', surge de la crisis del universalismo cristiano frente a la excepcionalidad americana: ¿cómo explicar el modo de dispersión de los animales y humanos desde un solo punto (el Arca) hasta todos los lugares más alejados del mundo conocido? ¿Cómo pudieron atravesar cordilleras y mares? Y, más aún, ¿cómo explicar que en los continentes lejanos de Europa, como América, Asia y África, haya animales y plantas diferentes de los de Europa? ¿Es que todos no estaban en el Arca?

Apelando al mito platónico de la Atlántida, Kircher sugiere la hipótesis ad hoc de que con posterioridad al diluvio, al formarse los mares, subsistió a lo largo de todo un periodo un medio de comunicación intercontinental: "Desde Europa y África pudieron llegar sin dificultad a ambas Américas, ya que en el Océano Atlántico hubo una gran isla o continente, como hemos indicado anteriormente siguiendo a Platón, quien afirma que fue muy frecuentado por los expedicionarios griegos y egipcios, lo que ampliamente describimos en Mundus Subterraneus" *.

La otra pregunta, ¿cómo es posible explicar la diversidad de animales en otras áreas geográficas?, es largamente debatida por Kircher, llegando a conclusiones cercanas a las hipótesis de Buffon: "En lo referente a los animales muy distintos a los nuestros, que muchos se sorprenden de encontrar en las regiones de las Indias, éstos dejarán de sorprenderse si entendieran correctamente lo que dijimos sobre la transformación de los animales de las especies primeras en el segundo libro de esta obra, ya que su constitución ha variado en función del cielo y de los climas" $\dagger$.

Para Kircher, la primera conjetura es que estos se 'transformaron' por influencia del clima o de la zona geográfica: “... todas las especies naturales, tanto vegetales como sensitivas, al ser trasladadas

¥ “Prefacio" a Mundus Subterraneus ... (1665), cap. I, "Sobre la ocasión de esta obra y sobre los viajes del autor" $\left({ }^{26}\right), p$. 21.

Kircher $\left({ }^{37}\right)$, lib. 3, part. III, cap. III.

Ibid.

Ibid., part. I, sec. III, cap. III.

Ibid. de un clima o zona a otro, cambian de comportamiento e incluso de constitución, de forma que una misma e idéntica especie en los primeros siglos ha sido hallada con una sorprendente constitución en el Nuevo Mundo o en las Indias" La segunda conjetura - de la 'degeneración postdiluviana' - es una hipótesis que un siglo después retomó Buffon (1779) en 'Las Épocas de la Naturaleza' $\left({ }^{38}\right)$. La tercera conjetura para explicar la mayor diversidad de seres vivos con posterioridad al diluvio es: "al multiplicarse los animales sobre la Tierra en el transcurso del tiempo y ocupar las selvas, los montes y los campos, surgieron nuevos animales procedentes de la mezcla de varias especies" $\$$.

Lo que queremos sugerir con este trabajo es que la tradición organicista en la que se encuentra envuelta la obra de Unanue es una pista importantísima para entender nuestra tradición científica nacional, en la que convergieron diversas vertientes doctrinarias y sociales del mundo antiguo y moderno fusionadas en la tradición organicista -poco estudiada hasta el presente- sobre la que se ha construido la tradición científica moderna en el Perú. Ello puede, quizá, evitar en el futuro que sigamos reproduciendo la 'sorpresa' que tuvo Humboldt hace dos siglos al leer el texto de Unanue y encontrar en él una sólida tradición teórica y práctica acumulada desde fines del siglo XVI, que refutaba de manera patente el supuesto 'atraso de los peruanos' en su proceso de modernidad.

Tal vez dicho examen nos puede ayudar a evaluar hoy tanto nuestras debilidades como nuestras ventajas comparativas en la tarea de desarrollar una cultura científica moderna en el Perú. Es posible que el predominio de la tradición organicista en nuestra comunidad científica nacional haya sido un gran obstáculo para el desarrollo de ciertas disciplinas científicas en las que fructificó el paradigma mecanicista (particularmente en las ciencias físicas), pero es también cierto que el paradigma organicista constituyó un fuerte estímulo para el desarrollo de las llamadas ciencias biológicas, las cuales han alcanzado considerables desarrollos en el Perú. Este es un asunto particularmente importante después de que la paradigmática tradición mecanicista -hegemónica entre los siglos XVII y XIX- ha sido objeto de demoledores asedios críticos a lo largo de siglo XX en la comunidad científica internacional, dando lugar a la búsqueda de paradigmas de cientificidad más potentes y complejos que los que hasta entonces dominaron el horizonte de la ciencia moderna. 


\section{Referencias bibliográficas}

1. Salazar-Bondy A. El saber, la naturaleza y Dios en el pensamiento de Hipólito Unanue. [Tesis para optar el grado de Bachiller en Filosofía, Mimeo., 243 pp.]. Lima: UNMSM; 1950.

2. Unanue H. Introducción a la descripción científica de las plantas del Perú. Mercurio Peruano. N. ${ }^{\circ}$ 43. p. 69.

3. Unanue H. Observaciones sobre el clima de Lima y su influencia en los seres organizados, en especial el hombre. $2^{\mathrm{a}}$ ed. Madrid, 1815.

4. Unanue H. Relación del Gobierno del Virrey don Gil de Taboada. Obras. T. III. p. 267.

5. Unanue H. Observaciones sobre el clima de Lima y su influencia en los seres organizados, en especial el hombre. $5^{a}$ edición. Lima: Comisión Nacional Peruana de Cooperación Intelectual; 1940.

6. Unanue H. Geografía Física. Mercurio Peruano. N. ${ }^{\circ}$ 106, p. 26.

7. Unanue H. Primer ensayo filosófico del entendimiento humano. Mercurio Peruano. N. ${ }^{\circ}$ 372. p. 205.

8. Unanue H. Discurso histórico sobre el nuevo camino del Callao. Obras. T. II. p. 180.

9. Unanue H. Decadencia y Restauración del Perú. Mercurio Peruano. N. ${ }^{\circ} 221$. p. 110.

10. Unanue H. Disertación sobre la coca. Mercurio Peruano. $\mathrm{N}^{\circ}$ 375. p. 233.

11. Unanue H. Discurso para el establecimiento de unas conferencias clínicas de Medicina. Mercurio Peruano. $\mathrm{N}^{\circ}$ 371. p. 200-2.

12. Unanue H. Memoria del Ministro de Gobierno y Relaciones Exteriores. Obras. T. II. p. 384.

13. Unanue H. Copia de una carta. Mercurio Peruano. $\mathrm{N}^{\circ} 24$, p. 226.

14. Unanue H. Disertación sobre el tabaco. Mercurio Peruano. $\mathrm{N}^{\circ} 108$. p. 36.

15. Unanue H. Fiestas linneanas. Obras. T. II. p. 397.

16. Unanue H. Geografía física del Perú. Mercurio Peruano. $\mathrm{N}^{\circ}$ 106. pp. 19-20.

17. Unanue H. Noticia de los trajes. Mercurio Peruano. $\mathrm{N}^{\circ} 79$.

18. Unanue H. Introducción a la descripción de las plantas del Perú. Mercurio Peruano. $\mathrm{N}^{\circ}$ 44. p. 77.

19. Sequeiros L. El padre José de Acosta (1540-1600): misionero, naturalista y antropólogo en América hispana. Granada: Proyección; 2000. XLVII. pp. 63-74.

20. Guamán Poma de Ayala F. Nueva Corónica y buen gobierno. Ed. Franklin Pease G. Y. Lima: Fondo de Cultura Económica; 1993. (3 vols)

21. Pease F. Prólogo. En: Huamán Poma de Ayala, Nueva Corónica y buen gobierno. vol. 1. p. XXV.

22. Capel H. Organicismo, fuego interior y terremotos en la ciencia española del siglo XVIII. Barcelona: Cuadernos GeoCrítica; 1980. No 27/28. p. 1-94.

23. Capel H. La Física Sagrada. Creencias religiosas y teorías científicas en los orígenes de la geomorfología española. Barcelona: Ed. del Serbal; 1985. p. 223.
24. Durand J. El Inca Garcilaso de América. Lima: Biblioteca Nacional del Perú; 1988.

25. Iberico M. Discurso sobre el Inca Garcilaso de la Vega, Revista Histórica, Cusco. 1939. № 73.

26. Kircher A. Athanasii Kircheri e Soc. Iesu. Mundus Subterraneus, in XII Libros digestus; quo Divinum Subterrestris Mundi Opificium, mira Ergasteriorum Naturae in eo distributio, verbo pantamorfon Protei Regnum, Universae denique Naturae Majestas et divitiae summa rerum varietate exponuntur. Amsterdam: Apud Joannem Janssonium et Elizeum Weyestraten; 1665. vol. 1, p. 346. vol 2, p. 487.

27. López de Velasco J. Geografía y descripción universal de las indias. Madrid: BAE; 1971. T. CCXLVIII.

28. Humboldt A. Aspects of nature, in different lands and different climates with scientific elucidations [1826] Philadelphia: Lea and Blanchard; 1850.

29. Humboldt A. Ensayo político sobre el reino de la Nueva España. México: Porrua; 1991.

30. Humboldt A. Sitios de las Cordilleras y monumentos de los pueblos indígenas de América. Madrid: Imprenta y librería de Gaspar; 1878. [Otras ediciones: Buenos Aires, 1968; México: Siglo XXI Ed., 1995, (2 vols)].

31. Humboldt A. Cristóbal Colón y el descubrimiento de América. Caracas: Monte Ávila Editores; 1992.

32. Humboldt A. Cosmos. Ensayo de una descripción física del mundo. Trad. de Bernardo Giner y José de Fuentes. Madrid: Imprenta de Gaspar y Roig (4 tomos); 1874-75.

33. Valdés. Retórica cristiana. Roma; 1579.

34. Acosta J de. Historia natural y moral de las Indias. Madrid: Atlas BAE 73; 1954 [1590].

35. Humboldt A. Voyage aux régions equinocciales... París, 1807-1839 (6 partes, 30 vols.). Cf. Versión en español: Viaje a las regiones equinocciales del Nuevo Continente. Caracas: Monte Ávila; 1991 (5 vols).

36. Rebok S. Alexander von Humboldt y el modelo de la 'Historia Natural y Moral'. La versión preliminar de este trabajo se presentó en el Simposio El género americano de las 'historias naturales y morales: un modelo cognoscitivo de la diversidad cultural desde el mundo latino. Organizado por Fermín del Pino, Leoncio López-Ocón y Rafael Chabrán en el marco del XXI International Congress of History of Science; 2001 del 8-14 de julio; Ciudad de México.

37. Athanasii Kircheri e Sos. Iesu Arca Noë in tres libros digesta... Ámsterdam; 1675, pp.240. [Edición española: El Arca de Noé. El mito, la naturaleza y el siglo XVIII. Edición de A. Martínez Tomé. Madrid: Ed. Octo.; 1989. p. 319].

38. Buffon G, Leclerc L. Las épocas de la Naturaleza [1779]. Madrid: Alianza Universidad; 1997. p. 429.

Manuscrito recibido el 15 de noviembre de 2005 y aceptado para publicación el 10 diciembre de 2005.

Correspondencia: Dr. José Carlos Ballón

Felix Dibós 980, Magdalena. Lima 17, Perú

Correo-e: jcballonsur@hotmail.com 